\title{
Cracking simulation-based cumulative fatigue damage assessment
}

\author{
mah farag ${ }^{1}$, Ramy El-kady ${ }^{1}$, and M Hammouda ${ }^{1}$ \\ ${ }^{1}$ Al-Azhar University
}

March 12, 2021

\begin{abstract}
This work is an extension of applying a previously developed fracture mechanics cracking damage model to predict the fatigue lifetime of un-notched round specimens made of a ferrite-pearlite $0.4 \mathrm{C}-70 / 30$ carbon steel in some cases of variable amplitude loading VAL. The model simulates the collective behavior of growing short fatigue cracks originating from the specimen surface roughness. Material grains of different phases, sizes and strengths are randomly distributed over the minimum circumference. Possible activities of surface cracks are predicted against loading cycles. Relevant published experimental data were utilized for comparison. The present predictions are in agreement with the corresponding experimental results.
\end{abstract}

\section{Cracking simulation-based cumulative fatigue damage assessment}

M. M. Farag*, R. M. El-Kady, M. M. I. Hammouda

Mechanical Engineering Department, Faculty of Engineering, Al-Azhar University, Nasr City, Cairo, Egypt

*Corresponding Author

Mobile: 00021063104067

E-mail: eng.mahfarag2010@gmail.com

\section{ABSTRACT}

The present work is an extension of applying a previously developed fracture mechanics cracking damage model to predict the fatigue lifetime of un-notched round specimens made of a ferrite-pearlite $0.4 \mathrm{C}-70 / 30$ carbon steel in the cases of (a) two-step fully reversed axial loading with low-to-high and high-to-low sequences and (b) repeated application of fully reversed two-step axial loading blocks. This model numerically simulates the collective behavior of growing short fatigue cracks originating from the specimen surface. The surface roughness is assumed resembling micro cracks of different sizes and locations along the minimum specimen circumference. Material grains of different phases, sizes and strengths are randomly distributed over that circumference. Possible activities of surface cracks are predicted against loading cycles till fracture occurs. Published experimental data on ferritic-pearlitic steel specimens in fully reversed variable amplitude loading were utilized. Different specimens were randomly configured and virtually tested. The present predictions are in a fair agreement with the corresponding experimental results.

\section{KEYWORDS}

Fracture mechanics, Short fatigue cracks, Ferritic-pearlitic steel, Surface roughness, Endurance curve, Cumulative fatigue damage

\section{NOMENCLATURE}

\begin{tabular}{ll}
\hline$A_{c} \quad$ total cracked area \\
\hline$l \quad$ surface crack length
\end{tabular}




\begin{tabular}{ll}
\hline$A_{c}$ & total cracked area \\
\hline$l_{\mathrm{av}}$ & average length of the existing surface cracks \\
$\mathrm{N}$ & number of cycles \\
$\mathrm{N}_{\mathrm{f}}$ & number of cycles to failure \\
$Z$ & number of existing surface cracks \\
$\Delta_{\mu}, \Delta_{S}$ & extent of monotonic and cyclic, respectively, crack tip plastic zone \\
$\delta, \Delta \delta$ & maximum and cyclic, respectively, crack tip opening displacement \\
$\sigma$ & current applied stress amplitude \\
$\sigma_{o}$ & initial axial stress amplitude \\
$\sigma_{\psi}$ & monotonic yield stress \\
$\sigma_{S \psi}$ & cyclic yield stress \\
\hline
\end{tabular}

\section{ABBREVIATIONS}

\begin{tabular}{ll}
\hline CAL & Constant Amplitude Loading \\
\hline CDC & Cracking Damage Configuration \\
CSA & Constant Stress Amplitude \\
FCG & Fatigue Crack Growth \\
FEA & Finite Element Analysis \\
HCF & High Cycle Fatigue \\
H-L & High-to-Low \\
L-H & Low-to-High \\
VAL & Variable Amplitude Loading \\
VL & Variable Loading \\
SMC & Specimen Minimum Circumference \\
TSL & Two-Step-Load \\
\hline &
\end{tabular}

\section{INTRODUCTION}

Fatigue life prediction of engineering components is the end target of numerous research efforts ${ }^{1}$. The experimental questions have been tackled mainly via constant amplitude loading (CAL), and to a lesser extent via variable loading (VL) despite its more relevance to the in-service conditions ${ }^{2}$. Yet the VL are typically simplified to repeated blocks of loading cycles ${ }^{3}$. Those CAL studies result typically in a reliable $\mathrm{S} / \mathrm{N}$ endurance data. The dependence on specific material properties, geometrical, surface and environmental parameters of the fatigue life is evaluated through extensive testing ${ }^{4}$. With the objective of understanding the effect of VL, two-step loading of either the same type or different types with different sequences were experimentally and theoretically investigated.

Fatigue damage develops with cycle-by-cycle accumulation, even when stress levels are below the material's fatigue limit for most of the loading history. After the accumulated damage reaches a critical value fracture would ensue ${ }^{5}$. Cracking is a form of accumulated damage.

The commonly held view that fatigue life of a component is divided into crack initiation phase and a subsequent crack propagation phase have witnessed over the last two decades several relaxations ${ }^{6}$. Specifically with the initiation period being subdivided into initiation plus micro-structurally short crack growth phases. Fatigue cracks initiate from the most favorable surface or subsurface sites, e.g. ${ }^{7}$, geometrical imperfections, favorably oriented grains, non-metallic inclusions or brittle precipitates. Below the fatigue limits of steels cracks are frequently observed propagating but subsequently arrested. Thus, small crack growth ${ }^{6}$ are gradually becoming more popular. In un-notched components fatigue cracks can originate from the roughness of their surface ${ }^{8}$ with initial sizes comparable to local micro-structural features rendering the linear elastic 
fracture mechanics characterization of crack growth invalid ${ }^{9}$. Elastic-plastic fracture mechanics has been used to characterize the behavior of such short cracks ${ }^{10}, 11$. In addition of cracking, other forms of fatigue damage have been recognized.

Early on, it was recognized that an energy-based damage parameter can unify the damage caused by different types of loading such as thermal cycling, creep, and fatigue. A unified theory based on the total strain energy density was presented by Ellyin and his coworkers ${ }^{12}$. The total strain energy per cycle is decomposed into plastic and elastic strain energies. The plastic strain is the one responsible for the damage, while the elastic portion associated with the tensile stress drives the crack growth.

Another approach attempting such a unification of damage accumulation, is the continuum damage mechanics $(\mathrm{CDM})^{13}$. This approach was originally proposed by Kachanov ${ }^{14}$ and Rabotnov ${ }^{15}$ in treating creep damage problems. Chaboche and Lesne ${ }^{16}$ were the first to apply CDM to fatigue life prediction. For the one-dimensional case, they postulated that fatigue damage evolution per cycle can be generalized by a function of the load condition and damage state. By correlating the changes in tensile load-carrying capacity and the effective stress concept, they idealized damage evolution through a nonlinear continuous damage (NLCD) model. Based on the CDM concept, many other forms of fatigue damage equation have been developed, as described by Fatemi and Yang ${ }^{17}$. Basically, all these CDM-based approaches are very similar to the NLCD model in both form and nature. The main differences lie in the number and characteristics of the parameters used in the model, the requirements for additional experiments, and their applicability. CDM models were mainly developed for uniaxial fatigue loading.

In the case of variable amplitude loading (VAL), fatigue life prediction uses the full $S / N$ curve established through CAL testing. The Palmgren-Miner linear damage rule was the first in that direction ${ }^{2,18}$. That rule has the shortcomings of not considering interaction and sequence effects ${ }^{17}$ as well as its inability to recognize damages taking place in the low-cycle fatigue ( $\mathrm{LCF})$, where the dominant failure mechanism is identified as the macroscopic strain. As a result, many different fatigue damage models have been proposed to remedy those deficiencies. Some models, e.g. due to Makkonen ${ }^{19}$, require the evaluation of some material-dependent parameters through extensive testing which may not be available to design engineers, causing some difficulties in fatigue life estimation. Other models do not need such extensive testing. An example is the damage curve approach due to Gao et al. ${ }^{20}$ which is based on a similar work by Manson et al. ${ }^{21}$. Shang and Yao ${ }^{22}$ proposed another simple continuum fatigue damage model which considered the effect of mean stress.

Mesmacque et al. ${ }^{23}$ developed a damage rule which utilized only the full $S / N$ curve of the material and the von Mises stress as a damage indicator. Siriwardane et al. ${ }^{24}$ applied that rule to estimate the remaining fatigue life of railway bridges and a significant deviation was reported between predicted and in-service lives and, thus, they developed ${ }^{25}$ a similar rule using a plastic meso-strain as the damage indicator instead. Other models applied the concept of iso-damage curves in a nonlinear damage model utilizing the material full $S / N$ curve to analyze fatigue lifetime under VL ${ }^{26}$. A bi-linear cumulative damage model ${ }^{27}$ is an example of such an approach. This model was used to predict residual lifetimes for cases of two-step loading (TSL) with high-low $(\mathrm{H}-\mathrm{L})$ and low-high $(\mathrm{L}-\mathrm{H})$ sequences. Other nonlinear cumulative fatigue damage models ${ }^{28-33}$ were developed and used to show their capabilities to predict the fatigue lifetime of notched and un-notched specimens due to VL.

Some researchers considered the accumulation of fatigue damage by deformation processes, e.g. ${ }^{34}$. Other cumulative fatigue damage models were based on ductility exhaust and crack propagation, e.g. ${ }^{35}$. The concept that fatigue cracking damage accumulates with applied cycles was invoked in the literature both experimentally and theoretically. Miller and Zachariah ${ }^{36}$ and Miller and Ibrahim ${ }^{37}$ used an exponential cumulative fatigue damage law to demarcate the fatigue crack initiation and short crack propagation in un-notched round specimens in torsion and push-pull. They (1) used two different laws for the fatigue growth during the two phases of initiation and short crack propagation and (2) assumed the roughness of the specimen surface resembling surface micro cracks.

Some published theoretical and experimental researchers analyzed the shape of the front of a surface crack 
38, 39 .The front is curved rather than straight. Some woks in the literature assumed a surface crack front with the geometry of a circular arc, ${ }^{40-46}$. In some other works, a crack depth equal to half of the surface crack length is manipulated ${ }^{42,} 44$.

Existing cumulative fatigue damage models based on cracking consider a single or isolated dominant crack. This inevitably over-estimates the fatigue lifetime of the specimen as the coalescence of interacting in-plane and out-of-plane cracks shortens the time to failure ${ }^{47-51}$. Further, the individual short crack behavior imposes great difficulty in regard to modeling the very early stages of crack growth as individual cracks are susceptible to large changes in growth rate depending on their exact lengths and position relative to micro structural barriers, the features of the random distribution of the grains along with other mechanical and metallurgical effects. Great efforts are still needed to obtain an appropriate generalized prediction model for cumulative fatigue damage.

Farag et al. ${ }^{52}$ developed a numerical 2D elastic-plastic fracture mechanics model, called herein after FRH cracking model, to simulate the collective growth behavior of short cracks originating from the surface roughness of un-notched round specimens made of a two-phase alloy in constant amplitude axial fatigue loading. The model assumed the pre-existence of tiny cracks of different sizes and locations on the specimen surface due to its roughness. The features of the random distribution of the material grains were considered in terms of their sizes and micro-structural phases along with their mechanical properties. For convenience, a succinct description of the original model follows.

\section{FRH CRACKING MODEL}

Material grains of different sizes, phases and mechanical properties are assumed randomly arranged along the specimen minimum circumference (SMC). The specimen surface roughness resembles multi coplanar micro cracks with different sizes existing at the center of each grain along the SMC. The front of a crack is assumed having the geometry of a circular arc ${ }^{40-46}$. The crack depth is assumed equal to half of the surface crack length as manipulated in some relevant works found in the literature ${ }^{42,44}$. The crack length determines the corresponding crack area. A specimen with an initial configuration as described is cyclically loaded.

Consequently, some grains experience plastic deformation. The tip of a crack in an elastically deformed grain has a plastically deformed zone given by the crack size, the applied stresses and the grain yield stresses. Thus, the stress-strain regime existing at the two opposing tips of two adjacent cracks in two neighboring grains enables the estimation of the extents of the plastic zones at both tips. The rate of advance of a crack tip is estimated by making use of the surface crack length, the extents of the monotonic and cyclic plastic zones ahead of the tip and the average shear strain within the plastically deformed zones.

After N load cycles, (1) some surface cracks become longer, (2) the total cracked area increases (3) the area of the supporting ligament decreases, (4) the tip of a crack has the possibility of either advancing or stop propagating and (5) the two opposing tips of some adjacent cracks approach and possibly stop at a distance or merge to form one crack. A linear coordinate system is devised along the SMC to continuously trace the location of the tips of the existing cracks.

As a result of that cracking activity the following two scenarios are possible, i.e. (1) when the applied stress is greater than the material's fatigue limit $\sigma_{F}$, the supporting ligament becomes unable to withstand the applied load after the application of a finite $\mathrm{N}$ load cycles and, hence, the specimen breaks, (2) In case of the applied stress be less than $\sigma_{F}$, all existing cracks become non-propagating at some load cycles and, thus, the specimen remains unbroken after the application of a relatively large $\mathrm{N}$ load cycles. The details of the original model can be found elsewhere ${ }^{52}$.

The model was applied to predict the fatigue lifetime of un-notched round specimens made of a ferritepearlite $0.4 \mathrm{C}-70 / 30$ carbon steel in push-pull axial loading. This cracking simulation enabled an assessment of the specimen's fatigue lifetime and the endurance $S / N$ curve of the material with its fatigue limit could, thus, be assessed. Figure 1 presents the prediction of that simulation in the HCF regime compared with published experimental results ${ }^{3}$. Further, the model recognized the effect of surface roughness, specimen 
size and mean stress on fatigue lifetimes ${ }^{52}$.

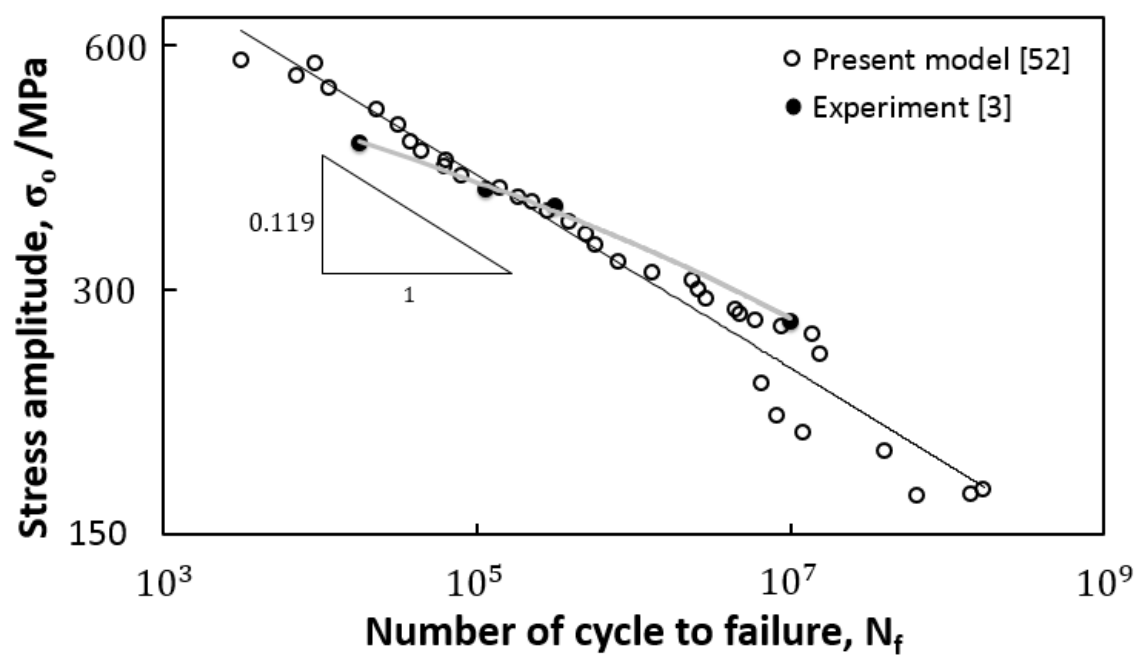

Fig. 1 Fatigue lifetime predicted by the present cracking simulation in the HCF regime for CSA virtual tests

\section{PRESENT WORK}

The present work is an extension of this model to predict the fatigue lifetime of un-notched round specimens made of a ferrite-pearlite $0.4 \mathrm{C}-70 / 30$ carbon steel in the cases of (a) two-step fully reversed loading with different sequences and (b) repeated application of fully reversed loading blocks.

Table 1 Experimental parameters of (a) two sets of two-step loading tests; (b) repeated two-step loading block tests.

(a)

\begin{tabular}{|c|c|c|c|c|c|c|c|c|}
\hline \multirow[t]{2}{*}{ Test } & Туре & $\begin{array}{l}1^{\text {st }} \text { Loading } \\
\text { level }\end{array}$ & $\begin{array}{l}1^{\text {st }} \text { Loading } \\
\text { level }\end{array}$ & $\begin{array}{l}1^{\text {st }} \text { Loading } \\
\text { level }\end{array}$ & $\begin{array}{l}2^{\text {nd }} \\
\text { Loading } \\
\text { level }\end{array}$ & $\begin{array}{l}2^{\text {nd }} \\
\text { Loading } \\
\text { level }\end{array}$ & $\begin{array}{l}2^{\text {nd }} \\
\text { Loading } \\
\text { level }\end{array}$ & $\begin{array}{l}\text { Cycles } \\
\text { fracture }\end{array}$ \\
\hline & & $\sigma_{\mathrm{O} 1} \mathrm{MPa}$ & $\mathrm{N}_{\mathrm{F} 1}$ & $\mathrm{~N}_{1}$ & $\sigma_{\mathrm{O} 2} \mathrm{MPa}$ & $\mathrm{N}_{\mathrm{F} 2}$ & $\mathrm{~N}_{2}$ & \\
\hline 1 & H-L & 432.5 & 39665 & 25002 & 390 & 194968 & 37171 & 62173 \\
\hline 2 & L-H & 390 & 194968 & 100005 & 432.5 & 39665 & $33411^{6}$ & 133416 \\
\hline
\end{tabular}

(b)

\begin{tabular}{|c|c|c|c|c|c|c|c|}
\hline $1^{\text {st }}$ Loading & $1^{\text {st }}$ Loading & $1^{\text {st }}$ Loading & $2^{\text {nd }}$ Loading & $2^{\text {nd }}$ Loading & $2^{\text {nd }}$ Loading & Cycles to & Tests \\
\hline level & level & level & level & level & level & fracture $\mathrm{N}_{\mathrm{f}}$ & \\
\hline$\sigma_{\mathrm{O} 1} \mathrm{MPa}$ & Blocks $B_{1}$ & $\begin{array}{l}\text { Cycles/block } \\
\mathrm{N}_{1}\end{array}$ & $\sigma_{\mathrm{O} 2} \mathrm{MPa}$ & Blocks $\mathrm{B}_{2}$ & $\begin{array}{l}\text { Cycles/block } \\
\mathrm{N}_{2}\end{array}$ & & \\
\hline \multirow[t]{3}{*}{425} & 16 & 1000 & 415 & 15 & 5000 & 91780 & $\mathrm{~T} 1$ \\
\hline & 10 & & 400 & 10 & 10000 & 107319 & $\mathrm{~T} 2$ \\
\hline & 10 & & 385 & 10 & 20000 & 207811 & T3 \\
\hline \multirow[t]{3}{*}{387.5} & 14 & 15000 & 425 & 14 & 1 & 229957 & $\mathrm{~T} 4$ \\
\hline & 16 & & & 16 & 10 & 262769 & $\mathrm{~T} 5$ \\
\hline & 13 & & & 13 & 100 & 199179 & T6 \\
\hline
\end{tabular}


The present work virtually simulates the experimental tests due to De Los Rios et al. ${ }^{3}$ with the loading configurations shown in Table 1. The tests were carried out in air. Those tests used un-notched solid round specimens made of a ferrite-pearlite $0.4 \%$ carbon steel. The material had an ultimate tensile stress equal to $580 \mathrm{MPa}$ and an average monotonic yield stress $\sigma_{y}=400 \mathrm{MPa}$. The minimum diameter of the specimens was $7.3 \mathrm{~mm}$. The mean grain size was $36 \mu \mathrm{m}$ with a standard deviation equal to $13 \mu \mathrm{m}$.

Table 1(a) lists two sets of experimental parameters corresponding to two-step cumulative fatigue damage. Those tests are simulated as follows. From the predicted $S / N$ curve, the average number of cycles to fracture at the two stress ranges $\sigma_{o 1}$ and $\sigma_{o 2}$ are $N_{f_{1}}$ and $N_{f_{2}}$ respectively. A specimen is randomly configured and virtually tested at $\sigma_{o 1}$ for $N_{1},<N_{f_{1}}$, cycles. The stress range $\sigma_{o 2}$ is, then, applied for $N_{2}$ cycles when fracture takes place. The two stress levels are utilized to execute virtual tests with L-H and H-L sequences. Further, the test is repeated with specimens having the same configuration but with different values of $\frac{N_{1}}{N_{f_{1}}}$.

The experimental parameters of six repeated two-step block loading tests, T1-T6, are listed in Table 1(b). The parameters of a test are (1) the stress amplitude $\sigma_{o 1}$ of the first loading block which is applied for $N_{1}$ cycles and (2) the stress amplitude $\sigma_{o 2}$ of the second loading block which has $N_{2}$ cycles. A randomly configured specimen is virtually tested for $N_{1}$ cycles at $\sigma_{o 1}$ and, then, for $N_{2}$ cycles at $\sigma_{o 2}$. That loading configuration is repeated till the fracture of the specimen. Further, the test is repeated with 7 specimens having different surface configurations.

\section{SPECIMEN CONFIGURATION}

The specimens alloy has volume percentages of $70 \%$ and $30 \%$ respectively for the ferrite and pearlite phases. The mixture rule concludes average values for $\sigma_{y}$ equal to $275.9 \mathrm{MPa},=\sigma_{y 1}$, for the ferrite grains and 689.7 $\mathrm{MPa},=\sigma_{y 2}$, for the pearlite grains. Search in the literature shows that values up to $\sigma_{y 1}=312 \mathrm{MPa}$ and $\sigma_{y 2}=1020 \mathrm{MPa}$ can be found. Thus, standard deviations of $35.9 \mathrm{MPa}$ and $331 \mathrm{MPa}$ are invoked for $\sigma_{\mathrm{y}}$ of the ferrite and pearlite grains respectively. Variations in $\sigma_{y}$ of the grains of each phase are assumed randomly distributed between the minimum and maximum values of the corresponding phase. The cyclic yield stress of steel is approximately equal to 0.6 of its monotonic yield stress ${ }^{11,12,5,53-55}$. Following that, a grain is assumed having a value of 0.6 for the ratio of its cyclic and monotonic yield stresses.

A mean grain size of $36 \mu \mathrm{m}$ is assumed for both phases of the alloy with $13 \mu \mathrm{m}$ standard deviation. This accommodates surface 445 ferrite grains and 191 pearlite grains arranged along the circumference of the specimen minimum cross section.

The specimen surface roughness resembles micro cracks of different sizes and locations. The model assumes the existence of multi coplanar micro cracks along the specimen minimum circumference. The starting maximum crack length is $0.1 \mu \mathrm{m}$ and the crack lengths follow a normal distribution.

Different virtual specimens were randomly prepared with the above configuration. A virtual test starts with one of those specimens. A specimen is subjected to a cyclic axial load with the parameters listed in Table1.

\section{TESTING SIMULATION}

A virtual test starts with one of the above configured specimens. The specimen is subjected to a cyclic axial load corresponding to the parameters given for one of the experiments listed in Table 1. Consequently, some grains are plastically deformed. A grain is considered experiencing plastic deformation when the current applied stress is greater than its yield stress.

The extents of the monotonic and cyclic plastic zones ahead of the tip of a crack are assumed given by either (1) carefully calculated extents based on fracture mechanics concepts in terms of crack length, applied stress and yield stresses of the grains located ahead of the tip or (2) the extent of plasticity within the grains located ahead of the tip, whichever is greater. The applied load and the extents of the crack tip plastic zones calculate corresponding maximum and cyclic crack tip opening displacements which are, then, used for the calculation of the advance rate of the considered tip. The details of those calculations are given elsewhere 37. 
All existing tips are subjected to the above calculations. An increment of load cycles is accommodated to capture the earliest event out of (1) a maximum tip advance of $0.1 \mu \mathrm{m},(2)$ a maximum approach of adjacent tips of two neighboring cracks of $0.1 \mu \mathrm{m}$ (3) the earliest merge of two approaching tips and (4) the instant of changing the applied load as given in Table 1. The resulting advance of the tips updates their coordinates within the surface grains. With the updated configuration of the existing cracks, a computational loop terminates. The flow chart of a computer software devised to follow and repeat the above algorithm for further computational loops is shown in Fig. 2.

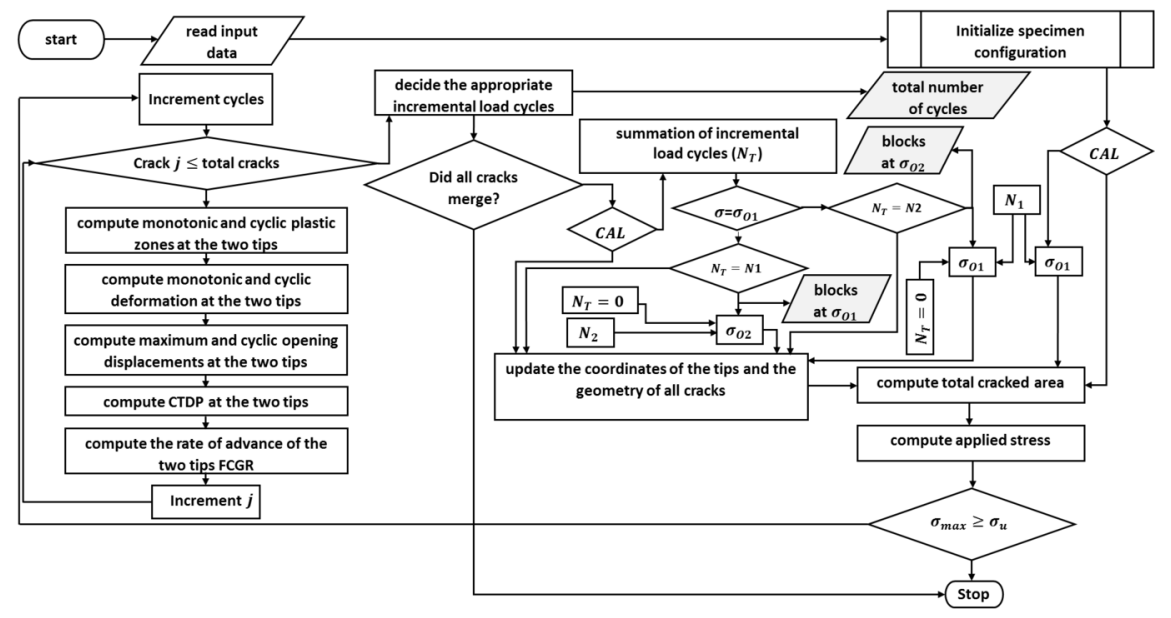

Fig. 2 Flow chart of the computer program developed in the present work

With an increase in the load cycles, (1) the total cracked area $A_{C}$ increases, (2) the supporting ligament area decreases, (3) the current stresses increase, (4) the two adjacent tips of some neighboring cracks approach and (5) the extent of the plastic zones ahead of the tips of some cracks is altered. As a consequence, the tip of a crack may either advance or stop propagating. Thus, the adjacent tips of neighboring two cracks either stop their advance at a distance or the two cracks coalesce.

In the case of a CAL, the following two scenarios are possible. Should the amplitude of the applied stress be greater than the fatigue limit of the material, fracture of the specimen takes place after the application of some load cycles when the ligament area becomes unable to support the current applied maximum stress. The second scenario happens when applied stress amplitude is less than the fatigue limit of the material. In this case, all existing cracks stop their propagation after a number of loading cycles and the specimen remains unbroken after a number of loading cycles greater than $10^{7}$.

The program was run to trace possible events of fatigue growth behavior of the existing surface cracks due to the application of one of the loading patterns listed in Table 1. In this case, the possibility is to have the first scenario. Different specimens were randomly configured and virtually tested.

\section{RESULTS AND DISCUSSION}

Some issues relevant to the present work have been addressed for discussion in the previous publication due to Farag et al. ${ }^{52}$ on cracking simulation-based fatigue life assessment due to CAL. Examples are (1) the inability of the stress intensity factor to correlate the behavior of short cracks at high stresses, (2) the utilization of a correlation between fatigue crack growth (FCG) rates and a devised crack tip deformation parameter equal to $\delta^{0.46} \Delta \delta^{0.5}$ for both long and short cracks, where $\delta$ and $\Delta \delta$ are the maximum and cyclic crack tip opening displacements, (3) the plastic zone interaction between the two opposing tips of adjacent cracks when the two tips are approaching each other, (4) The similar behavior of $A_{C}$ and the total length of cracks existing on the specimen surface and (5) the extreme difficulty in the present model of considering the evidence of microstructure evolution of crack initiation. In this publication ${ }^{52}$, the present authors reviewed some works 
in the literature in relation to the fatigue behavior of long and short cracks in un-notched specimens under CAL. Here, results of the present simulation due to the application of some patterns of VAL are presented and discussed. As demonstrated below, the discussion of the present results is in need of some results due to $\mathrm{CAL}^{52}$.

The present work utilized one numerical simulation considering one surface finish to have all the present results. Different specimens were randomly configured, virtually tested at different stresses and consequently their $S / N$ curve was constructed as shown in Fig. 1. A single experimental endurance data point was utilized to adjust the proposed modeling to the experimental data. The necessity of such an adjustment had been expected in advance before the first run of the present simulation. The expressions for the crack tip deformation utilized in the present model ${ }^{52}$ are the result of an elastic-plastic finite element analyses FEA previously performed for a trough-thickness crack in a plate ${ }^{56}$. The present crack system is different and, thus, the geometrical factor used in the mathematical form of the stress intensity factors was employed. Alternatively, similar 3D FEA have to be performed to analyze curved surface crack from the surface of round bars.

The model considers growing fatigue micro cracks, $\leq 0.1 \mu \mathrm{m}$, originating only from the roughness of a round specimen surface. Many metallurgical and mechanical factors, manufacturing operations, surface treatments, cleaning and handling have strong influences on surface roughness. For example, fine turning with a tool peak radius of $0.5 \mathrm{~mm}$, and feed $0.13 \mathrm{~mm}$ can achieve an average peak-to-valley height of $4 \mu \mathrm{m}$. Values as small as $0.05 \mu \mathrm{m}$ can be achieved by honing. In between values are obtainable by appropriate surface finish processes such as grinding and lapping. In order to correlate these surface roughness parameters to the present model, the metrologist and the production engineer can easily measure the surface roughness in terms of maximum peak-to-valley height and mean surface roughness. From those two values the standard deviation of the surface roughness can be determined. In the present model the average surface roughness is identified as an average initial crack depth, and its standard deviation given by a typical statistical analysis of metrological surface measurement. The maximum value of crack length was $0.1 \mu \mathrm{m}$ according to the relevant experimental data available for the same specimens ${ }^{3}$.

Some of the variables utilized to devise the present model are assumed randomly distributed. These include grain size, starting crack size and monotonic and cyclic yield stress of the grains of the two phases of the specimens' material. The parameters of the mean value and standard deviation of the grain size and material's straight can be controlled with proper heat treatments whilst those parameters controlling the starting crack size are given by the roughness of the specimen surface. With this assumption, the present simulation is closer to reality. Further, randomization is invoked (1) to distribute the grains of the two phases of the material along the minimum circumference of the specimen and (2) to select one of the virtually configured specimens to run a specific virtual test. This process is uncontrolled.

The present simulation is based on the collective behavior of growing short fatigue cracks originating from the specimen surface. The model utilizes $A_{C}$ as a measure of fatigue damage. The results of the present work can easily show that the behavior of $A_{C}$ with the number of cycles is similar to that of the total length of the existing cracks. On the other hand, the cracking-based cumulative fatigue damage models existing in the literature consider the length of a single isolated dominant crack $34,36,37,47-51$. This is expected to over-estimate the fatigue lifetime for the interaction and coalescence of existing small cracks shorten the time to failure ${ }^{47-51}$. Further, an individual crack shows large changes in its growth rate. This depends on the features of that crack in terms of its size and position relative to micro structural barriers along with other mechanical and metallurgical effects.

Figures 3I-3IV present examples to demonstrate the anomalous growth behavior of four short surface cracks, labeled as crack 4, crack 306, crack 406 and crack 556, individually traced throughout one of the virtual CAL tests with a stress amplitude equal $390 \mathrm{MPa}$. Fifteen, nineteen, eleven and twenty-three neighboring short cracks are involved in the cracking activities illustrated respectively in Figs. 3I-3IV.

As an example, a description of the cracking activities demonstrated in Fig. 3I follows. The involved fifteen 
neighboring short cracks are sequentially numbered from left to right. The growth of the crack labelled 4 is assumed continuously monitored throughout the test. The two tips of that crack commence their advance with the start of the test till $\mathrm{N}=35200$ cycles when its length becomes $24 \mu \mathrm{m}$, see Fig. 3I(A). The crack length, then, suddenly achieves a length of $110.9 \mu \mathrm{m}$, see Fig. 3I(B), due to its coalescence with a neighboring crack $86.8 \mu \mathrm{m}$ long located at its right and composed of the two already merged cracks 5 and 6 . The resulting crack continues its growth, see Fig. 3I(B), from its two tips to reach $136.4 \mu \mathrm{m}$ at $\mathrm{N}=54647$ cycles when its left tip merges crack 3 to result in a crack $136.512 \mu \mathrm{m}$ long, see Fig. $3 \mathrm{I}(\mathrm{C})$, which grows continuously from both tips to achieve $145 \mu \mathrm{m}$ at $\mathrm{N}=54650$ cycles before it coalesces with the growing coalesced cracks 2 and 1 to have a crack of a total length equal to $241.88 \mu \mathrm{m}$. As $\mathrm{N}$ increases, the two tips of the resulting crack advance to achieve a length equal to $246.78 \mu \mathrm{m}$ at $\mathrm{N}=182364$ cycles, see Fig. 3I(C), when its right tip merges the left tip of a growing adjacent crack composing of nine coalesced small cracks to suddenly reach a length of $561.1 \mu \mathrm{m}$. For a better illustration, Fig. 3I(A-C) are plotted with different scales.
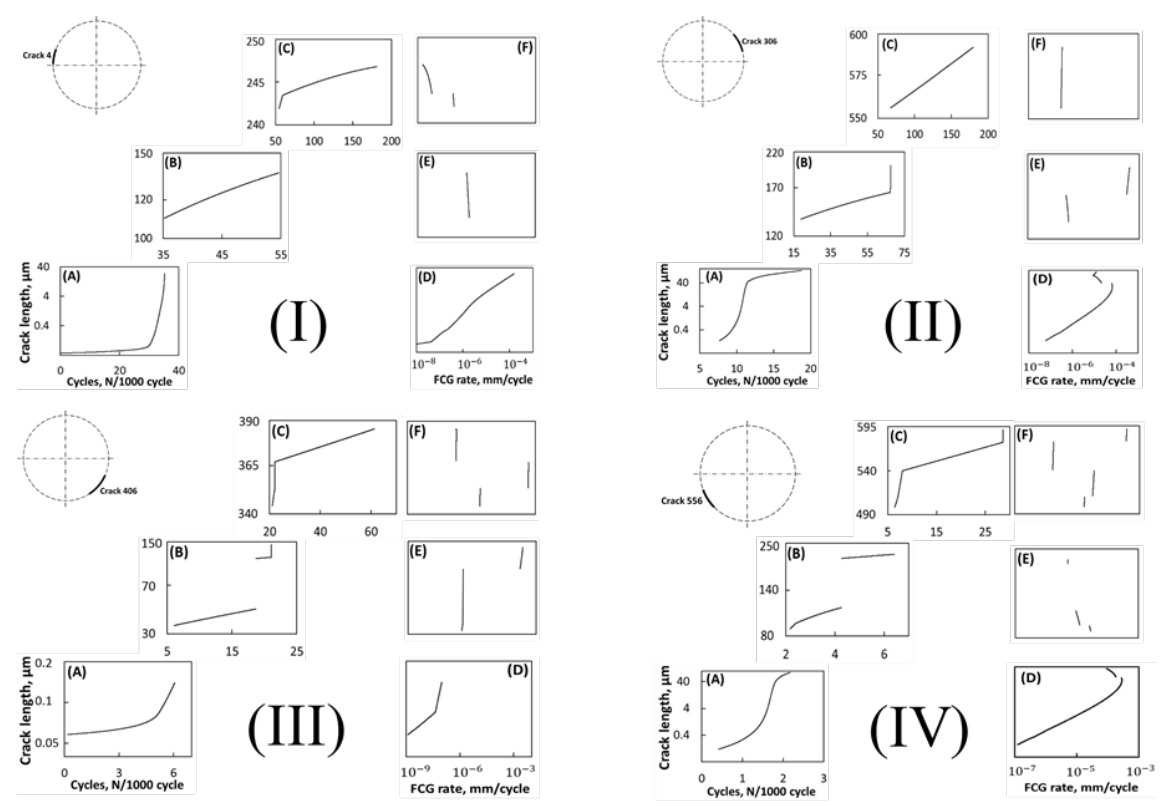

Fig. 3 Example to demonstrate the anomalous growth behavior of a short surface crack individually traced throughout one of the virtual CAL tests with a stress amplitude equal $390 \mathrm{MPa}$.

As given by the present simulation, the FCG rate of crack 4 during its three stages presented in Fig. 3I (A)-(C) is plotted in Fig. 3I (D)-(F). The crack starts its growth with a very low rate and continues to propagate with an increasing rate, see Fig. 3I (D). Beyond its first coalescence, the crack growth is relatively slower, Fig. 3I (E). During the third stage of its propagation, see. Fig. 3I (F), the crack continues its growth with decreasing rates. According to the present model, that behavior is due to the local variation in the yield stresses of the involved surface grains and the extents of the plastically deformed zones ahead of the tips of the interacting cracks.

The interaction and evolution of short fatigue cracks and their coalescence were clarified in the literature via replica and acoustic microscopy observations, e.g. ${ }^{57}$. However, the number of static images, typically $=7-15$ for each specimen is too small to describe all the kinematic events possibly taken place over the specimen surface throughout its life. For example, the advance rate of the two tips of a crack may be different, the coalescence of neighboring cracks may be missed and the events taken place during the period of successive replicas are not observed. To simulate the replica technique, an illustrating example follows considering the behavior of crack 4 presented in Fig. 3. 
Figure 4 shows the fatigue crack growth behavior of that crack should its surface length be measured at intervals of (1) 10000 cycles, Fig. 4(A), (2) 20000 cycles, Fig. 4(B), and (3) 30000 cycles, Fig. 4(C). The behavior corresponding to the three intervals is different as compared with each other and with that behavior presented in Fig. 3I(D-F). Thus, to have reliable experimental results, the number of replicating actions should be thought of.

\section{Hosted file}

image5.emf available at https://authorea.com/users/401152/articles/513349-cracking-
simulation-based-cumulative-fatigue-damage-assessment

Fig. 4 Fatigue growth behavior of a short surface crack whose results are presented in Fig. 3 should its length be measured at intervals of (A) 10000 cycles, (B) 20000 cycles and (C), and 30000 cycles

The above example considers one crack out of fifteen cracks at a surface site. Should other individual cracks be in focus, difference in results is expected. Further, cracks existing at other surface sites are expected to have different activities. All the above aspects give rise to the experimentally observed anomalous fatigue growth behavior of short cracks.

Figure 5 shows examples of the computed $A_{C}$ plotted against the number of cycles $N$ as a result of running four virtual tests relevant to the experimental parameters listed in Table 1(a). The four runs started with the same specimen configuration. The two lines $\mathrm{O}-\mathrm{A}-\mathrm{D} \backslash$ and $\mathrm{OBC} \backslash$ present the results relatively out of the two constant stress amplitudes (CSA) $390 \mathrm{MPa}$ and $432.5 \mathrm{MPa}$. In both two-step loading (TSL) tests, the application of $\sigma_{o_{1}}$ for $N_{1}$ cycles results in a behavior similar to that given due to the application of the CSA of $432.5 \mathrm{MPa}$ and $390 \mathrm{MPa}$, i.e. the line O-A in Fig. 5 for the L-H sequence and the line O-B for the H-L sequence. The remaining life $\mathrm{N}_{2}$ at $\sigma_{o_{2}}$ results in $\sum \frac{N}{N_{f}}$ equal to 1.25 for the virtual L-H test and 0.79 for the H-L virtual test. Here, $N_{f}$ refers to the number of cycles to failure at a CSA test. The corresponding experimental $\sum \frac{N}{N_{f}}$ are 1.35 and $0.82^{3}$. The lines B-C and A-D give the duration $\mathrm{N}_{2}$ for the sequences L-H and H-L respectively. Another specimen differently configured was utilized to repeat the above four virtual runs with the same $N_{1}$. The resulting $\sum \frac{N}{N_{f}}$ is and 1.18 for the virtual L-H test and 0.83 for the H-L virtual test.

\section{Hosted file}

image6.emf available at https://authorea.com/users/401152/articles/513349-crackingsimulation-based-cumulative-fatigue-damage-assessment

Fig. 5 Examples of the assessment of the present simulation for the cracked area plotted against number of loading cycles for two-step loading tests with low-to-high, O-A-B-C, and high-to-low, O-B-A-D, sequences compared with the corresponding behavior due to the application of CSA virtual tests having the two involved stress amplitudes $390 \mathrm{MPa}, \mathrm{O}-\mathrm{A}-\mathrm{D} \backslash$, and $432.5 \mathrm{MPa}, \mathrm{O}-\mathrm{B}-\mathrm{C} \backslash$; (a) and (b) present the behavior of two specimens with different surface configurations.

Figure 6 presents the results of $A_{C}$ against $\frac{N}{N_{f}}$ for four virtual CSA tests. The figure shows that for a given

ratio of $\frac{N_{1}}{N_{f_{1}}}$ in TSL tests with L-H sequence, the ratio $\frac{N_{2}}{N_{f_{2}}}$ increases as the difference between the two involved stresses increases. With the H-L sequence, $\frac{N_{2}}{N_{f_{2}}}$ decreases with an increase in that difference. 


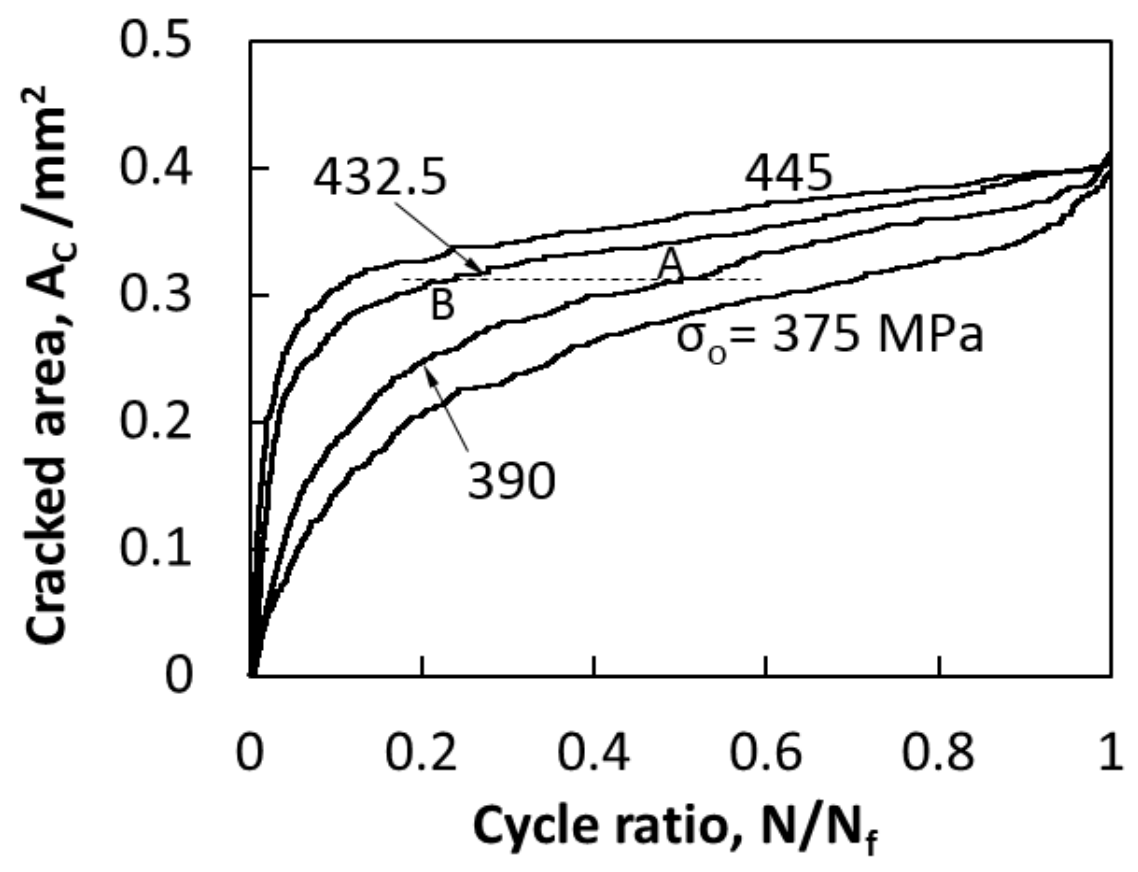

Fig. 6 Examples of the assessment of the present simulation for the cracked area plotted against cycles ratio due to the application of CAL having different stress amplitudes utilizing specimens with different surface configurations.

The results of the two virtual tests shown in Fig. 6 for the CSA of $432.5 \mathrm{MPa}$ and $390 \mathrm{MPa}$ are further considered in the form of $\mathrm{A}_{C}$ plotted against $\frac{N}{N_{f}}$. For the same $\frac{N}{N_{f}}$, the higher the stress amplitude the higher $A_{C}$ is. For the same $\mathrm{A}_{C}$, the lower the stress amplitude the higher $\frac{N}{N_{f}}$ is. The two points $\mathrm{A}$ and $\mathrm{B}$ in Fig. 5 are duplicate in Fig. 6. Figure 6 concludes that based on the results of the simulation of the CSA tests the $\sum \frac{N}{N_{f}}$ in the TSL with L-H sequence, $=S_{1}$, should be greater than 1 and in the case of H-L sequence $\sum \frac{N}{N_{f}},=S_{2}$, should be less than 1 .

However, Fig. 5 shows that the $\sum \frac{N}{N_{f}}$ given by the simulation of the corresponding TSL test with the L-H sequence is slightly less than $S_{1}$. Further, the $\sum \frac{N}{N_{f}}$ corresponding to the TSL test with the H-L sequence is appreciably less than $\mathrm{S}_{2}$. In spite of points $\mathrm{A}$ and $\mathrm{B}$ having equal $A_{C}$, the cracking damage configuration (CDC) of the specimen at point B due to the application of the CSA $432.5 \mathrm{MPa}$ and that at point A due to the application of the CSA $390 \mathrm{MPa}$ are different as discussed below. 


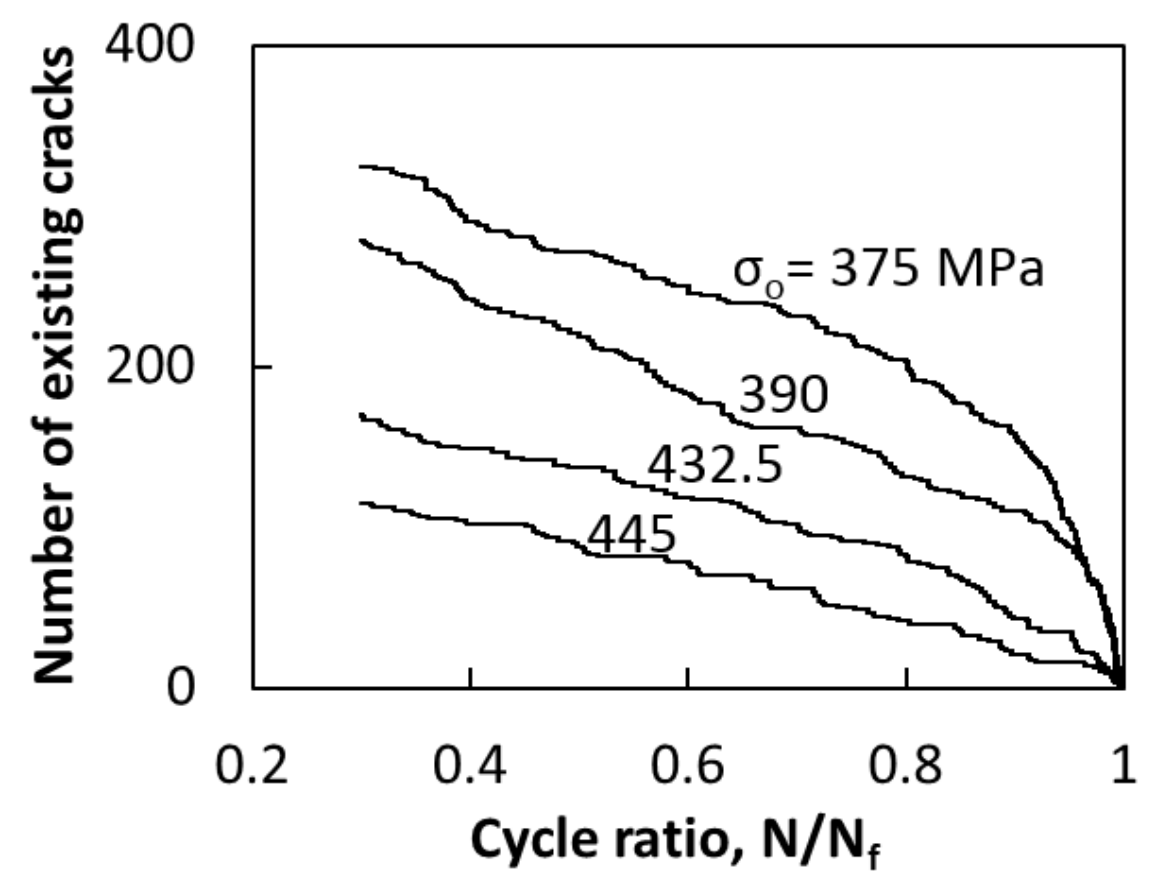

Figure 7 shows the variation of the number of existing cracks, Z, with $\frac{N}{N_{f}}$ for some CSA virtual tests. The activity of the coalescence of adjacent cracks increases as the applied stress and/or $\frac{N}{N_{f}}$ increase. Thus, the following two observations presented in Fig. 7 are obvious. For the same applied stress, Z deceases with increasing $\frac{N}{N_{f}}$. At a given $\frac{N}{N_{f}}, \mathrm{Z}$ decreases with increasing the applied stress.

Fig. 7 Examples of the assessment of the present simulation for the number of existing cracks plotted against cycle ratio due to the application of CAL having different stress amplitudes utilizing specimens with different surface configurations. 


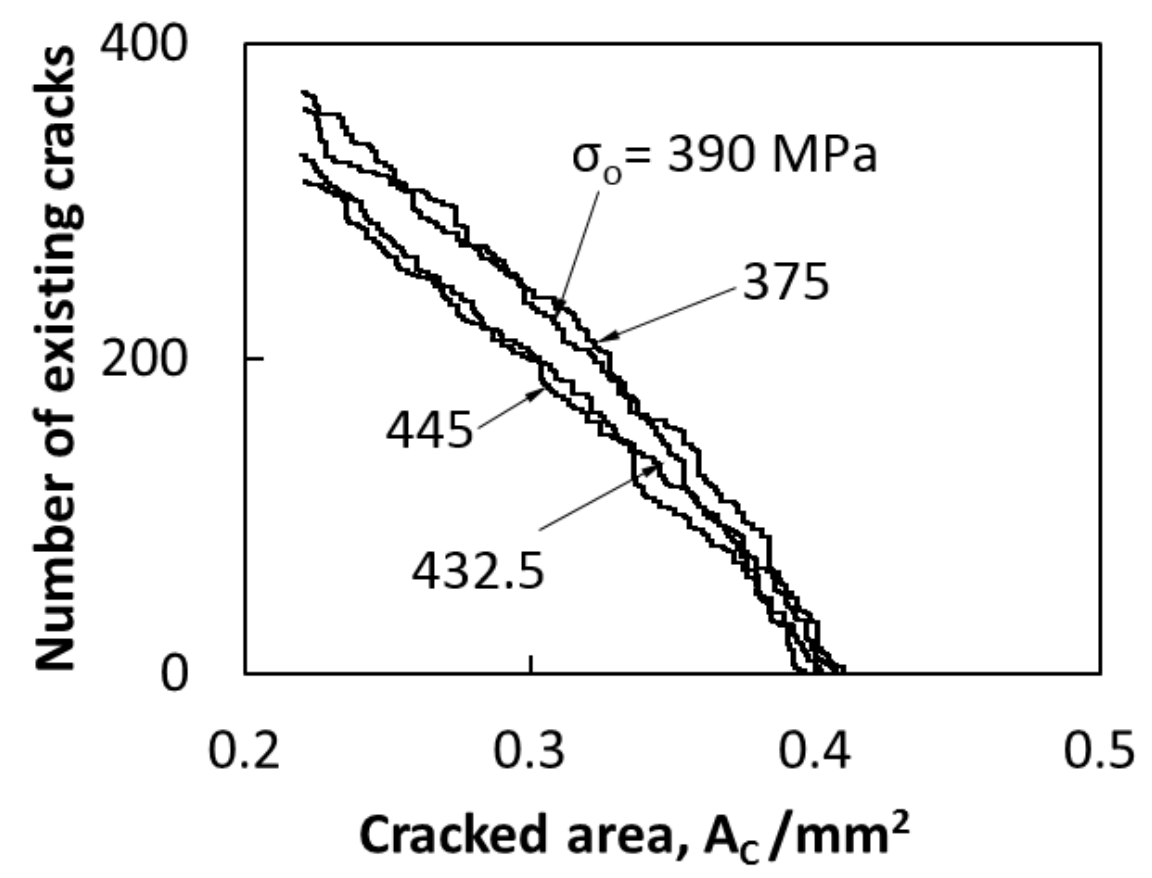

Fig. 8 Examples of the assessment of the present simulation for the number of existing cracks plotted against cracked area due to the application of CAL having different stress amplitudes utilizing specimens with different surface configurations.

In Fig. 8, $\mathrm{Z}$ is plotted against $A_{C}$ for different applied stresses. With a decrease in the applied stress and for the same $A_{C}$, there is an increase in $\mathrm{Z}$ and, hence, an increase in the number of advancing tips. The implication, here, is that for the same $A_{C}$ the average length of the existing surface cracks, $l_{\text {av }}$, decreases as the applied stress decreases. Figure 9 exhibits the variation of $l_{\text {av }}$ with the cycle ratio for different applied stresses as given by the present simulation. Both $\mathrm{l}_{\mathrm{av}}$ and $\mathrm{A}_{C}$ behave similarly. Figure 9 supports the experimentally observed $\sum \frac{N}{N_{f}}$ in the case of TSL tests with L-H and H-L sequences. 


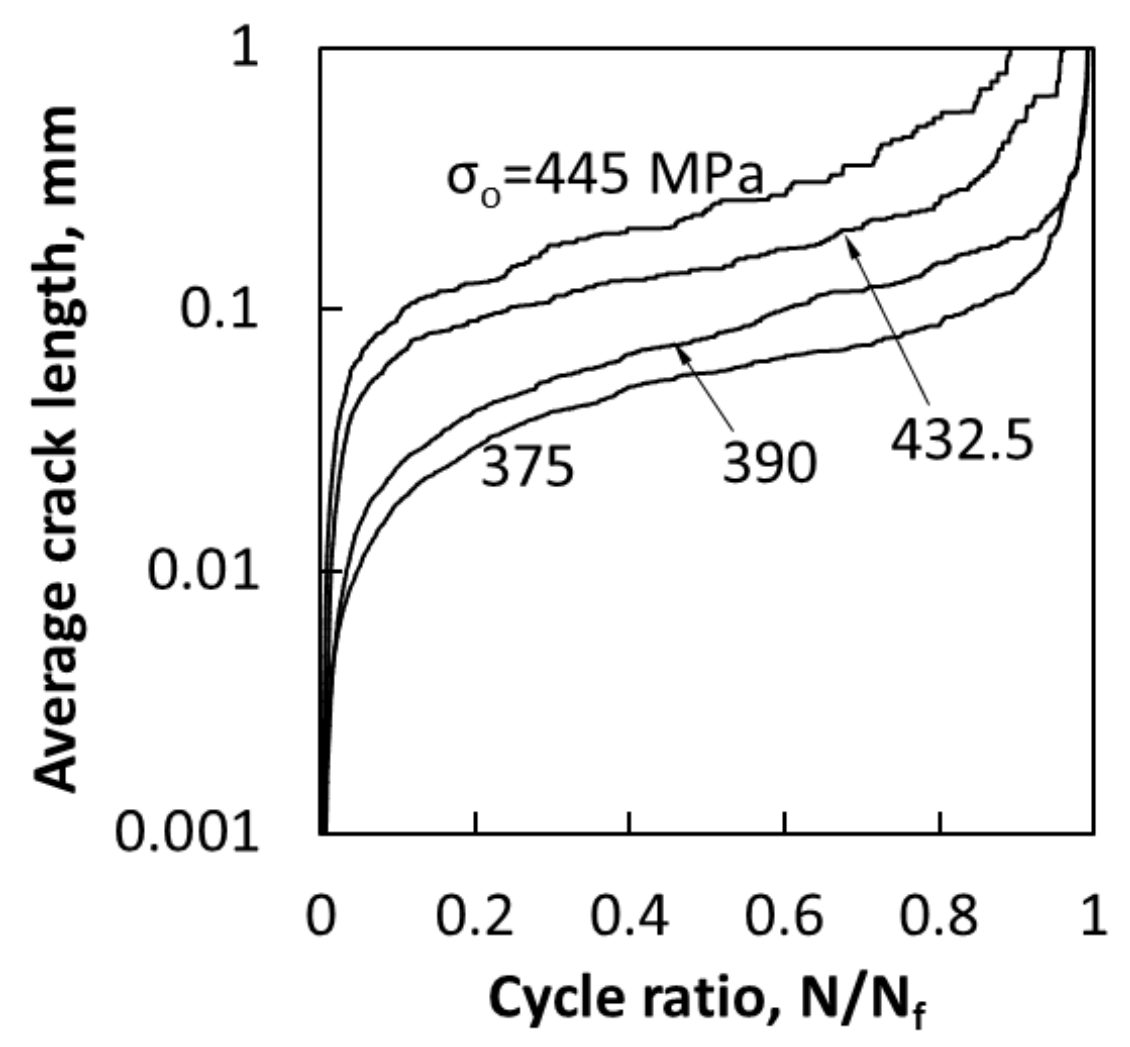

Fig. 9 Examples of the assessment of the present simulation for the average crack length plotted against cycle ratio due to the application of CAL having different stress amplitudes utilizing specimens with different surface configurations.

In the TSL test with the H-L sequence shown in Figs. 5 and 6, the specimen at point $\mathrm{B}$ due to the application of the CSA 432.5 MPa experiences less Z, and cracks relatively longer than those at point A due to the application of the CSA $390 \mathrm{MPa}$, Thus, this virtual test starts the application of the lower stress with relatively long cracks generated by the coalescence of smaller cracks at the higher stress. To illustrate, one of those long cracks is assumed generated by the coalescence of a number of smaller cracks. That crack can be easily proved to have a growth rate higher than the summation of the growth rates of the smaller cracks together. Thus, point $\mathrm{D}$ in Fig. 5 is on the left of point $\mathrm{D} \backslash$.

In the TSL test with the L-H sequence, the virtual test starts the application of the higher stress with relatively short cracks developed at the low stress compared with those cracks resulting in if the higher stress were applied from the start of the test. Following the above discussion of the behavior due to the H-L sequence, point $\mathrm{C}$ is expected on the right of point $\mathrm{C} \backslash$. However, point $\mathrm{C}$ in Fig. 5 is slightly on the left of point $\mathrm{C} \backslash$. The results of the present runs show that the rate of crack coalescence sharply increases for a period just after the start of the application of the higher load. That action adjusts to have the CDC of the specimen similar to that of the CSL at the higher load. The shift $\mathrm{C}-\mathrm{C} \backslash$ is due to the fast transition at the higher load from short cracks to relatively longer cracks.

The above two configured specimens were used to construct Fig. 10. This figure presents the results of virtual TSL tests utilizing the two stresses listed in Table 1(a) but at different ratios of $\frac{N_{1}}{N_{f_{1}}}$ with the L-H and H-L sequences together with the corresponding two experimental data. As experimentally observed in relevant literature, $\sum \frac{N}{N_{f}}$ is generally greater than 1 for the tests of L-H load sequence and $\sum \frac{N}{N_{f}}$ is less than 1 in the case of H-L load sequence. 


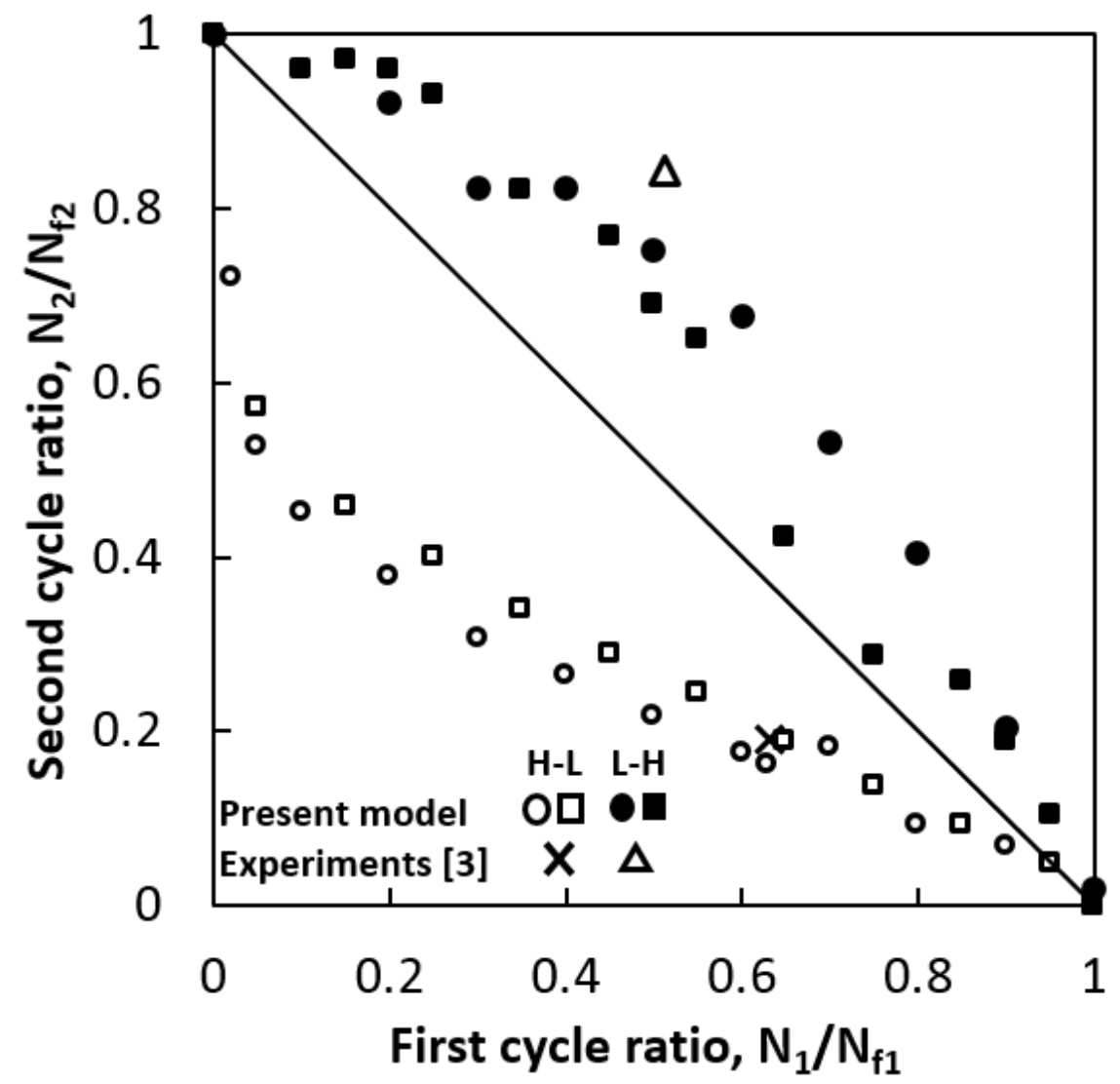

Fig. 10 Present prediction results of two-step loading tests having low-to-high, closed symbols, and high-tolow, open symbols, sequences with the two stress amplitudes of $390 \mathrm{MPa}$ and $432.5 \mathrm{MPa}$ and stress ratio $=$ -1 compared with available published experimental data ${ }^{3}$; The squared and circular symbols represent data of two specimens having different surface configurations.

Figure 11 plots the prediction of the present simulation against the corresponding experimental fatigue lifetime ${ }^{4}$ for the repeated two-step loading block tests with the parameters listed in Table 1(b). Each test was carried out seven times with different specimen configurations. The present prediction lies generally within the scatter band acceptable amongst the fatigue community. 


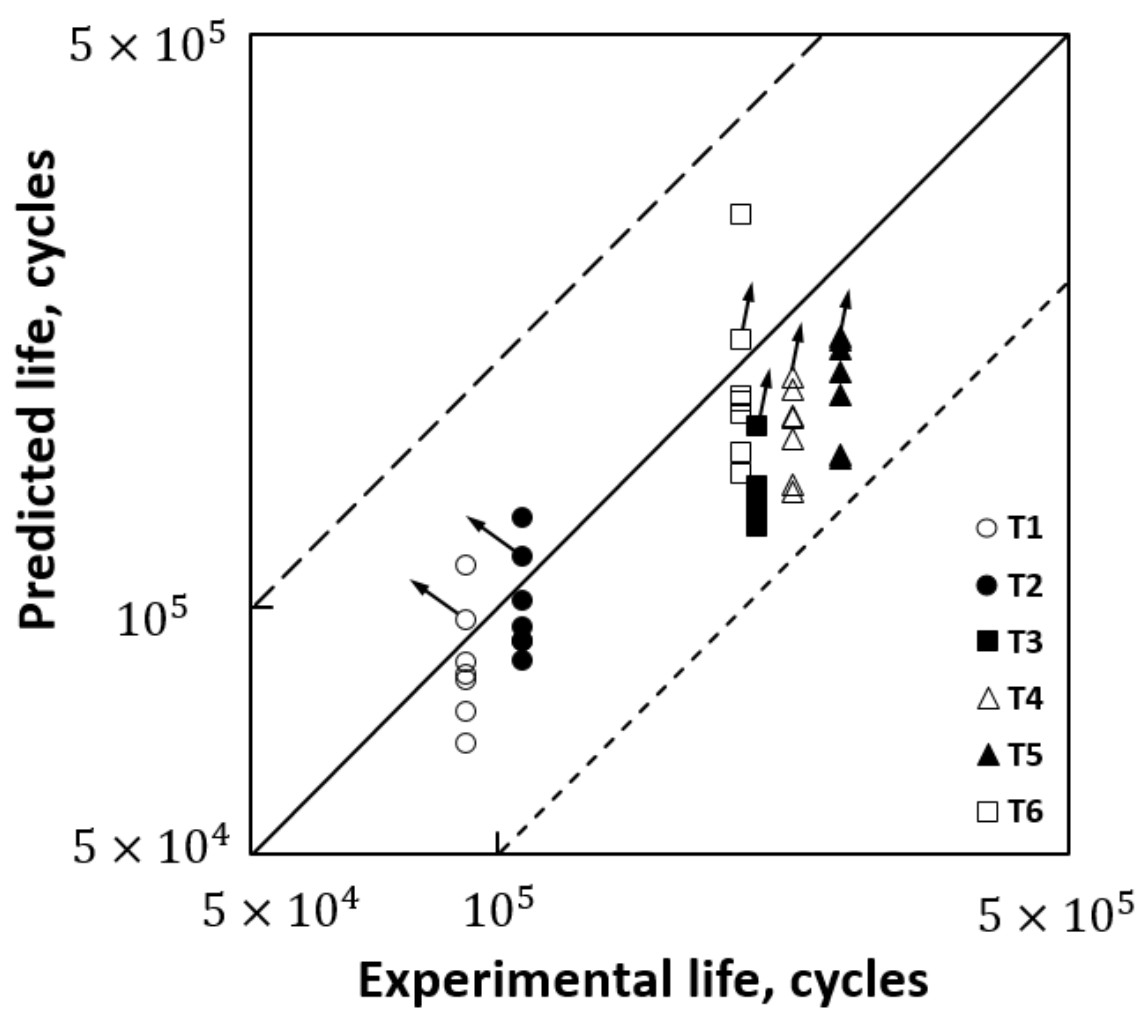

Fig. 11 Prediction of the present simulation against the corresponding experimental fatigue lifetime ${ }^{3}$ for six repeated two-step loading block tests, T1-T6, with the parameters listed in Table 1(b); Each virtual test was carried out seven times with different specimen configurations.

The stresses listed in Table 1 are higher than the material fatigue limit. The cracks analyzed in the present work are short and subjected to relatively high stresses. Most of those cracks grow in surface grains experiencing plastic deformation in the course of the tensile and compressive parts of the loading cycles. Thus, the well-known effect of the high load on the retardation behavior of the tips advancing in those grains as a result of changing the load to the low level is ignored ${ }^{58,59}$ in the present work. The results presented in Fig. 11 indicate that the lower load of a loading block is applied for a number of cycles less than that required for the full development of such an effect.

\section{Hosted file}

image13.emf available at https://authorea.com/users/401152/articles/513349-crackingsimulation-based-cumulative-fatigue-damage-assessment

Fig. 12 Examples of the assessment of the present simulation for the cracked area plotted against number of loading cycles for repeated two-step loading block tests compared with the corresponding behavior due to the application of CAL having the two involved stress amplitudes.

Figure 12 presents the cracked area against the corresponding number of cycles as a result of the present assessment for six examples out of the virtual tests involved in Fig. 11 together with their corresponding CAL virtual tests. The arrowed symbols in Fig. 11 refer to the examples presented in Fig. 12. A vertical line G-G is drawn in each figure to indicate $\mathrm{N}_{\mathrm{f}}$ experimentally obtained in the case of the presented repeated two-step block loading. The value of $\sum \frac{N}{N_{f}}$ for each experiment is typed in Fig. 12. The runs due to the CSA virtual tests result in their corresponding duration of $\mathrm{N}_{\mathrm{f}}$ which are used, here, to calculate $\sum \frac{N}{N_{f}}$. The theoretical summations are generally less than 1. This is justified in Fig. 12 which shows the behavior due 
to repeated two-step loading blocks. The line representing a repeated two-step loading blocks lies between the two corresponding CAL lines. For its corresponding three runs, the specimens in each example utilized the same surface configuration. Experimentally, summations equal to and greater than 1 are possible since specimens with different surface configurations are tested and calculations rely on CAL endurance data extracted from average fitted lines.

The four block parameters $\sigma_{o_{1}}, N_{1}, \sigma_{o_{2}}$ and $N_{2}$ have influences on $\sum \frac{N}{N_{f}}$. Keeping three of those parameters unchanged, such an influence of changing the fourth parameter follows. For $\sigma_{o_{1}}$ greater than $\sigma_{o_{2}}$, the previous discussion on the present results relevant to TSL tests with H-L sequence implies that $\sum \frac{N}{N_{f}}$ in repeated two-step loading block decreases with increasing $\frac{N_{1}}{N_{f_{1}}}, \frac{N_{2}}{N_{f_{2}}}$ and $\sigma_{o_{1}}$ and with a decrease in $\sigma_{o_{2}}$. The present simulation with its devised software is capable to perform a detailed parametric study for recognizing the contribution of each of the above parameters.

The present results together with those of its conjugate $\operatorname{article}^{52}$ are encouraging the present authors to work on checking the invoked model against other materials and geometries. Actually, the available four experimental data ${ }^{3}$ presented in Fig. 1 for comparison cover a lifetime range from $10^{4}$ cycles to $10^{7}$ cycles. The grey line in Fig. 1 presents the endurance line fitting those experimentally obtained point. Despite Fig. 1 shows good proximity between experimental data and the present model, it should be noted that the experimental data represent a small sample to be used as comparison, at maximum it can be stated as a possible indicator of compatibility. The same scenario is observed in Fig. 10, aggravated by the tiny available sample related to the experimental data. Of course, validation of the proposed model needs more comparative experimental sampling. Based on the above argument, the authors are working to check the model with sufficient experimental data on other two-phase and single phase materials available in the literature. That would be a strength of the model.

Relevant experimental data are numerous in the literature, e.g. ${ }^{55,60-65}$. Further, those publications specifically contain many test results with H-L and L-H load sequences. However, a problem exists. The input data necessary for the application of the model are the main parameters controlling the fatigue life of un-notched test specimens, i.e. (1) some metallurgical details of the tested material in terms of the existing phases with their percentage, grain size and mechanical properties, (2) specimen's size, (3) specimen's surface roughness, (4) loading pattern. Unfortunately, metallurgical details as mentioned above and/or surface roughness are not provided. At present, this unable the use of those test results to check the predictive abilities of the present model. However, the present algorithm can easily perform some comparative scenarios between two or more numerical simulations, considering different values of the missing data in a trial for their reasonable evaluation. This will facilitate the checking step.

The algorithm outlined by the flow chart in Fig. 2 applies the present model on the limited case of un-notched round specimens in push-pull loading. However, the concepts of the model can manipulate other uniaxial testing conditions, i.e. rotating bending moment and pure twisting moment. In this case, the algorithm needs some alterations to accommodate such conditions. For that objective, some numerical analyses should be performed for necessary deformation parameters around the tips of neighboring short surface cracks in the case of different types of uniaxial loading. Based on the above arguments, the authors will work to expand the application of the proposed model to other experimental tests with uniaxial loading.

\section{CONCLUSIONS}

The present work is an extension of applying a previously developed fracture mechanics cracking damage model to assess the fatigue lifetime of un-notched round specimens made of a two phase ferrite-pearlite 0.4C-70/30 carbon steel alloy in the cases of (a) two-step fully reversed axial loading with low-to-high and high-to-low sequences and (b) repeated application of fully reversed two-step axial loading blocks. The model simulates collective behavior of growing short fatigue cracks originating from the specimen surface roughness. The model is applied on different specimens with surface grains randomly configured in terms of their phase, size, strength and included crack size. The model identifies the development of possible activities of surface short cracks against loading cycles due to the application of the analyzed constant and variable amplitude 
loading. Comparison of published experimental fatigue lifetimes on ferritic-pearlitic steel specimens in fully reversed variable amplitude loading and the corresponding prediction shows fair agreement.

\section{REFERENCES}

1. Frost N. E. Marsh K. J. Pook L. P. Metal Fatigue. Clarendon Press Oxford UK; 1974.

2. Palmgren A. Die Lebensdauer von Kugellagern. Verfahrens-techinik. 1924; 68: 339-341.

3. De Los Rios E. R. Mercier P. El-Sehily B. M. Short crack growth behaviour under variable amplitude loading of shot peened surfaces. Fatigue Fract Engng Mater Struct. 1996; 19: 175-184

4. Santecchia E. Hamouda A. M. S. Musharavati F. Zalnezhad E. Cabibbo M. El-Mehtedi M. Spigarelli S. A review on fatigue life prediction methods for metals. Advances in Materials Science and Engineering. 2016; $1-26$.

5. Schijve J. Fatigue of structures and Materials. $2^{\text {nd }}$ ed. Springer; 2009.

6. Cui W. A state-of-the-art review on fatigue life prediction methods for metal structures. J Mar Sci. Technol. 2002; 7:43-56.

7. Nadot Y. Propagation lifetime from the surface and internal defects in the ultra-high cycle fatigue regime. The Open Materials Science Journal. 2008; 2: 35-39.

8. Takahashj K. Murakami Y. Quantitative evaluation of the effect of surface roughness on fatigue strength. Engineering against Fatigue Symposium. Sheffield, UK; 1997.

9. Hussain K. Short fatigue crack behaviour and analytical models: a review. Engineering Fracture Mechanics. 1997; 4: 327-354.

10. Miller K. J. The short crack problem. Fatigue Fract Engng Mater Struct. 1982; 3: 223-232.

11. Miller K. J. The behavior of short fatigue cracks and their initiation: part II- a general summary. Fatigue Fract Engng Mater Struct. 1987; 2: 93-113.

12. Ellyin F. Fatigue Damage, Crack Growth and Life Prediction, Springer, 1996.

13. Lemaitre J. Desmorat R. Engineering damage mechanics: ductile, creep, fatigue and brittle failures. Springer, 2005.

14. Valluri, S. R. A theory of cumulative damage in fatigue. Report No. ARL 182. Aeronautical Research Laboratory. Office of Aerospace Research. United States Air Force, 1961.

15. Scharton T. D. Crandall S. H. Fatigue failure under complex stress histories. ASME Journal of Basic Engineering. 1966; 88: 247-251.

16. Chaboche J. L. Lesne P. M. A non-linear continuous fatigue damage model. Fatigue Fract Eng Mater Struct. 1988; 11: 1-7.

17. Fatemi A. Yang L. Cumulative fatigue damage and life prediction theories: a survey of the state of the art for homogeneous materials, Int. J. Fatigue. 1998; 20: 9-34.

18. Miner M. A. J. Cumulative Damage in Fatigue. Journal of Applied Mechanics .1945; 67: A159-A164.

19. Makkonen M. Predicting the total fatigue life in metals. Int J Fatigue. 2009; 7: 1163-1175.

20. Gao H. Zuo F. Lü Z. Zhu S. Huang H. Residual life prediction based on nonlinear fatigue damage accumulation model. J Shanghai Jiaotong Univ. 2015; 4: 449-53.

21. Manson S. S. Halford G. R. Practical implementation of the double linear damage rule and damage curve approach for treating cumulative fatigue damage. Int J Fract. 1981; 2: 169-92. 
22. Shang D. G. Yao W. X. A nonlinear damage cumulative model for uniaxial fatigue. Int J Fatigue. 1999; 2: $187-94$.

23. Mesmacque G. Garciab S. Amrouchea A. Rubio-Gonzalez C. Sequential law in multiaxial fatigue, a new damage indicator. Int J Fatigue. 2005; 4: 461-7.

24. Siriwardane S. Ohgaa M. Dissanayakeb R. Taniwaki K. Application of new damage indicator-based sequential law for remaining fatigue life estimation of railway bridges. J Constr Steel Res. 2008; 2: 228-37.

25. Siriwardane S. Ohga M. Kaita T. Dissanayake R. Grain-scale plasticity based fatigue model to estimate fatigue life of bridge connections. J Constr Steel Res. 2009; 10: 1942-53.

26. Subramanyan S. A cumulative damage rule based on the knee point of the S-N curve. ASME J. Eng. Mater. Technol. 1976; 4: 316-21.

27. Ben-Amoz M. Cumulative damage model based on two-mode fatigue damage bounds. Materials Science and Engineering 2009; A 504: 114-123.

28. Aid A. Amrouche A. Bouiadjra B.B. Benguediab M. Mesmacque G. Fatigue life prediction under variable loading based on a new damage mode, Materials and Design. 2011; 32: 183-191.

29. Aid A. Bendouba M. Aminallah L. Amrouche A. Benseddiq N. Benguediab M. An equivalent stress process for fatigue life estimation under multiaxial loadings based on a new on linear damage model. Materials Science and Engineering. 2012; 538: 20-27.

30. Djebli A. Aid A. Bendouba M. Amrouche A. Benguediab M. Benseddiq N. A non-linear energy model of fatigue damage accumulation and its verification for Al-2024 aluminum alloy. Int J Nonlinear Mech. 2013; 51: $145-151$.

31. Benkabouche S. Guechichi H. Amrouche A. Benkhettab M. A modified nonlinear fatigue damage accumulation model under multiaxial variable amplitude loading. Int J Mech Sci. 2015; 100:180-194.

32. Peng Z. Huang H. Z. Zhou J. Li Y. F. A New Cumulative Fatigue Damage Rule Based on Dynamic Residual S-N Curve and Material Memory Concept. Metals. 2018; 456: 1-17.

33. Pavlou D. G. The theory of the S-N fatigue damage envelope: Generalization of linear, double-linear and non-linear fatigue damage models. Int J Fatigue. 2018; 110: 204-214.

34. Zhang W. Miller K. J. A study of cumulative fatigue damage under variable loading-mode conditions. Fatigue Fract Engng Mater Struct. 1996; 213: 229-239.

35. Kuroda M. Extremely low cycle fatigue life prediction based on a new cumulative fatigue damage model. International Journal of Fatigue. 2001; 24: 699-703.

36. Miller K. J. Zachariah K. P. Cumulative damage laws for fatigue crack initiation and stage I propagation, Journal of Strain Analysis. 1977; 4: 262-270.

37. Miller K. J. Ibrahim M. F. E. Damage accumulation during initiation and short crack growth regimes. Fatigue of Engineering Materials and Structures. 1981; 3: 263-277.

38. He Z. Kotousov A. Branco R. A simplified method for the evaluation of fatigue crack front shapes under mode I loading. Int. J. Fract. 2014; 188: 203-211.

39. Zakavi He B. Kotousov A. Khanna A. Branco R. On evaluation of fatigue crack front shapes. 9th Australas. Congr. Appl. Mech. ACAM. 2017; 27 - 29.

40. Wen J. F. Zhan Y. Tu S. T. Xuan F. Z. A combination rule for multiple surface cracks based on fatigue crack growth life. AIMS Mater. Sci. 2016; 3: 1649-1664.

41. Coules H. E. Interaction of surface cracks subjected to non-uniform distributions of stress. Int. J. Press. Vessel. Pip. 2017; 157: 20-29. 
42. Carpinteri A. Shape change of surface cracks in round bars under cyclic axial loading. Int. J. Fatigue.1993; 15, 21-26.

43. Caspers M. Mattheck C. Weighted averaged stress intensity factors of circular-fronted cracks in cylindrical Bars. Fatigue Fract. Eng. Mater. Struct.1987; 9: 329-341.

44. Toribio J.. Matos J. C. González B. Escuadra J. Compliance evolution in round cracked bars under tensile fatigue. Eng. Fract. Mech. 2011; 78: 3243-3252.

45. Seah T. T. Qian X. An interaction factor to estimate the over-constraining effect in plates with co-planar cracks. Eng. Fract. Mech. 2018; 199: 13-28.

46. Levan A. Royer J. Part-circular surface cracks in round bars under tension, bending and twisting. Int. J. Fract. 1993; 61: 71-99.

47. Navarro A. De Los R. E. R. Fatigue crack propagation modeling by successive blocking of dislocations. Proc R Soc. 1992; A437: 375-390.

48. Hobson P. D. Brown M. W. De Los Rios E. R. Two phases of short crack growth in a medium carbon steel, In. The Behavior of Short Fatigue Cracks (Edited by K. J. Miller and E. R. de los Rios). Mech. Engng Pub1. Inst Mech Engrs London. 1986; 1: 441-459.

49. Zhu C. A model for small fatigue crack growth. Fatigue Fract Engng Mater Struct. 1994; 17: 69-73.

50. Angelova D. Akid R. A note on modeling short fatigue cracks behavior. Fatigue Fract Engng Mater Struct. 1998; 21: 771-779.

51. Newmamn J. C. Ji. A review of modeling small-crack behavior and fatigue-life predictions for aluminum alloys. Fatigue Fract Engng Mater Struct. 1994; 17: 429-439.

52. Farag M. M. El-Kady R. M. Hammouda M. M. I. Cracking simulation based fatigue life assessment. Fatigue Fract Eng Mater Struct. 2020; 1-13.

53. Zhonghua L. Yimin L. Jinghua L. The development of stresses and their during cyclic loading. Fatigue Fract. Engng Mater. Strucl. 1993; 16: 781-794.

54. Gorash Y. MacKenzie D. On cyclic yield strength in definition of limits for characterisation of fatigue and creep behaviour. Open Eng. 2017; 7:126-140.

55. Watson P. Topper T. H. Fatigue-damage evaluation for mild steel incorporating mean stress and overload effects, Experimental mechanics, vol 12, 11-17, 1972.

56. Hammouda M. M. I. El-Sehily B. M. De Los R. E. R. The significance of crack tip deformation foe short and long fatigue cracks. Fatigue Fract Eng Mater Struct. 1995; 19: 475-484.

57. Rakitaky A. A. de los Rios E. R Miller K. J. Fatigue resistance of a medium carbon steel with a wear resistant thermal spray coating. Fatigue Fract Engng Mater Struct. 1994; 17: 563-570.

58. Hammouda M. M. I. Ahmad S. S. E. Sallam H. E. M. Correlation of fatigue crack growth by crack tip deformation behavior. Fatigue Fract Engng Mater Struct. 1995; 18: 93-104.

59. Hammouda M. M. I. Ahmad S. S. E. Sherbini A.S. Sallam H. E. M. Deformation behavior at the tip of a physically short fatigue crack due to single over load. Fatigue Fract Engng Mater Struct. 1998; 22: $145-151$.

60. Henry D. L. A theory of fatigue-damage accumulation in steel, Transactions of the ASME. 1955; 77: 913-918.

61. Corten H. Dolant T. Cumulative fatigue damage, IME-ASME Int. Conf. on Fatigue of Metals, London, September 235-246, 1956. 
62. VALLURI S.R. A unified engineering theory of high stress level fatigue, Aerosp. Eng., 20, 18-19, 68-69, October 1961.

63. Topper TH., Sandor B.I. Morrow J.D. Cumulative fatigue damage under cyclic strain control, Journal of Materials, 4(1), 189-199, March 1969.

64. T Bui-Quoc et al., Trans ASME, Journal of Basic Engineering, vol 93, 1971

65. Manson, S. S. Freche, 1. C. and Ensign, C. 11. Application of a Double Linear Damage Rule to Cumulative Fatigue. Fatigue Crack Propagation, ASTM STP 415, 386 (1967). 